\title{
Dynamic Microbial Network Structure and Assembly Process in Rhizosphere and Bulk Soils Along a Coniferous Plantation Chronosequence
}

\section{Ying Wang}

Northwest Agriculture and Forestry University

Liguo Dong

Northwest Agriculture and Forestry University

Min Zhang

Northwest Agriculture and Forestry University

Xiaoxiong Bai

Northwest Agriculture and Forestry University

Jiawen Zhang

Northwest Agriculture and Forestry University

Xuan Yu ( $\sim$ yuxnwsuaf@163.com )

Northwest Agriculture and Forestry University

\section{Research Article}

Keywords: soil microbial communities, co-occurrence pattern, assembly process, stochastic process, rhizosphere, afforestation

Posted Date: November 30th, 2021

DOI: https://doi.org/10.21203/rs.3.rs-1101835/v1

License: (c) (1) This work is licensed under a Creative Commons Attribution 4.0 International License. Read Full License 


\section{Abstract}

Aims: During plantation development, microbial composition and diversity are critical for the establishment of plant diversity and multiple ecosystem functions. Here we aimed to evaluate the impacts of chronosequence and soil compartment on the bacterial and fungal community compositions, species co-occurrence, and assembly processes in forest ecosystem.

Methods: Soils were collected in rhizosphere and bulk soils along a Pinus tabulaeformis plantation chronosequence $(15,30$ and 60 years old). The bacterial and fungal communities were determined using amplicon sequencing.

Results: The effect of stand age on the soil properties and microbial community structures was stronger than the effect of the soil compartment. In all soil samples, the dominant bacterial phyla were Proteobacteria, Acidobacteria, Actinobacteria, and Chloroflexi. Basidiomycota, Ascomycota, and Mortierellomycota were the dominant fungal phyla. Higher turnover rates of soil microbial communities were observed in rhizosphere soil than in bulk soil. Dispersal limitation governed the bacterial and fungal community assembly in all soil samples, and the fungal community was more susceptible to dispersal limitation. The bacterial and fungal keystone species compositions in the rhizosphere had significant positive correlations with the soil total phosphorus and nitrite nitrogen and total nitrogen and total phosphorus, respectively, indicating their importance in soil nitrogen and phosphorus cycling. The complexity of bacterial networks increased along the chronosequence. Fungal network complexity did not show a clear age-related trend but increased from bulk soil to the rhizosphere.

Conclusions: During Pinus tabulaeformis plantation development, soil microbial assembly was less environmentally constrained due to an increase in resource availability.

\section{Introduction}

In terrestrial ecosystems, soil microorganisms are crucial regulators in biogeochemical cycling and thus play important roles in preserving soil quality and function (Dobrovol'skaya et al. 2015; Wang 2018). The temporal and spatial variations in soil microbial communities might influence their ecological function (Liu et al. 2019). The rhizosphere is considered a biological microsite in the soil tightly surrounding the roots. The physicochemical properties of rhizosphere soil are completely different from those of bulk soil. Within a microsite, diverse root exudates promote the growth of microorganisms and increase their activities, which in turn enhance mineral acquisition, pathogen protection and abiotic stress tolerance (Canarini et al. 2019; Khan et al. 2021; Pascale et al. 2020). The nutrients derived from plants play a crucial role in regulating microbial abundance, activity, and diversity and thus impact the complex interactions among plants, soil microorganisms, and soil (Pascale et al. 2020; Xiong et al. 2021). In bulk soil, most of the soil microorganisms are in a dormant state due to carbon limitation (Rüger et al. 2021). It was reported that increases in root exudates might offset carbon limitation and trigger the activity of these bulk soil microorganisms (Meier et al. 2020). However, different amounts and compositions of root 
exudates only selected for and recruited the corresponding adapted plant species and genotype-specific microbes in the rhizosphere. The selection process led to significant differences in the species diversity and microbial interaction networks between the rhizosphere and bulk soil (Hartman and Tringe 2019). In recent years, most studies have focused on the microbial community structure and diversity of the rhizosphere as well as the driving factors in ecosystems, especially in forests (Goss-Souza et al. 2019; Yin and Yan 2020). The interactions among members of rhizosphere assemblages and the process of choosing niches based on functional traits in the rhizosphere remain unknown.

In an ecosystem, microorganisms live together and form complex co-occurrence networks based on various species interactions (Faust and Raes 2012). The species interactions related to potential intertaxa relationships and niches shared by community members are essential to understanding the role of soil microorganisms in maintaining ecosystem function and stability. Stochastic and deterministic processes are two fundamental ecological processes that shape communities in numerous habitats (Luan et al. 2020). The deterministic process is governed by environmental filtering, host selection (Vályi et al. 2016), and various biological interactions (e.g., predation, competition, mutualism, commensalism, and amensalism) (Zhou and Ning 2017), which result in obvious changes in community structure, especially higher $\beta$ diversity under divergent environmental conditions. Stochastic processes are involved in historical contingency (e.g., priority effects), ecological drift, and/or dispersal limitation that result in community structure patterns indistinguishable from random assemblages (Chase 2010). Both processes are essential for the assembly process of most communities (Liu et al. 2021). At smaller scales, the contribution of stochastic processes may overwhelm deterministic selection due to the reduction in habitat heterogeneity from bulk soil to the rhizosphere (Chase et al. 2014). Mendes et al. (2014) reported that the microbial community in the rhizosphere was filtered by a deterministic niche; in contrast, stochastic processes seemed to shape the microbial community in bulk soil. Therefore, the contribution of deterministic or stochastic processes in different habitats remains unclear. In addition, soil properties such as soil pH (Fan et al. 2018a), organic matter (Dini-Andreote et al. 2015; Tripathi et al. 2018), and total phosphorus (Xiong et al. 2010) are important factors controlling the microorganism assembly process. Plants can also impact soil microbial communities through rhizosphere effects (Li et al. 2019), host-microbial interactions (Hassani et al. 2018), and the indirect effects of soil physicochemical properties (Pugnaire et al. 2019). Plant growth (Guo et al. 2021), composition (Zhang et al. 2021), and diversity (Dang et al. 2018) were reported to affect soil microbial communities. It was deduced that plants might be an important driving factor affecting soil microbial community assembly.

The Loess Plateau, a semiarid and arid area located in Northwest China, has suffered serious land degradation due to perennial soil erosion. To mitigate soil erosion, extensive afforestation was carried out in the 1970s. Pinus tabulaeformis is widely planted in this region due to its adaptability to drought, cold, and barren soil (Bahram et al. 2013). There have been many reports about the effects of Pinus tabulaeformis plantations on soil nutrients, structure, and microbial communities (Dang et al. 2018; Song et al. 2021). However, these studies neglected the soil microbial assembly processes based on functional traits and the main driving factors of those processes. Therefore, in this study, we aimed to (1) investigate the changes in the microbial community structure, species co-occurrence networks, and assembly 
processes in rhizosphere and bulk soils along an age gradient of Pinus tabulaeformis plantations and (2) elucidate the underlying assembly mechanisms, e.g., the microbial co-occurrence relationships, the microbial ecological coexistence strategies, and the ecological assembly process shaping the bacterial and fungal communities. We hypothesized that (1) the rhizospheric microbial community structure and diversity, species co-occurrence networks, and keystone taxa differ from those of bulk soil due to the differences in biotic interactions and soil properties and that (2) the relative importance of deterministic and stochastic processes might change along a chronosequence because the interaction of plant communities and soil properties among different stand ages could exert selective pressure on soil microbial communities.

\section{Materials And Methods}

\subsection{Site description and soil sampling}

The study site was located at the Guanzhuang State-owned Ecology Experimental Forest Farm $\left(109^{\circ} 49^{\prime} 35.4^{\prime \prime} \mathrm{E}, 35^{\circ} 45^{\prime} 1.0^{\prime \prime} \mathrm{N}\right)$ in Huanglong County (Yan'an, Shaanxi, China). This area has a typical temperate continental semiarid to semihumid climate, with an altitude of 1,074-1,173 $\mathrm{m}$, a mean annual precipitation of $550 \mathrm{~mm}$ and a mean annual temperature of $9.2^{\circ} \mathrm{C}$. Precipitation occurs mainly from July to September, and the drought season lasts from winter to early summer of the next year. The soil is classified as a Calcaric Cambisol based on the Food and Agriculture Organization of the United Nations (FAO) classification.

The study was carried out in September 2019. Three Pinus tabulaeformis plantations aged 15, 30 and 60 years with similar geographical characteristics were selected as experimental sites (Table S1). Millet (Setaria italic) and corn (Zea mays) were the main crops before afforestation. To exclude spatial dependence, these experimental sites were less than $10 \mathrm{~km}$ apart from each other. Three $20 \mathrm{~m} \times 20 \mathrm{~m}$ plots were randomly selected at each experimental site. Rhizosphere and bulk soils, as the two soil compartments, were collected from each plot. Rhizosphere soil was defined as soil that is tightly attached to the roots (Liu et al. 2018). Five well-growing trees in each plot were selected randomly to obtain a representative rhizosphere soil sample. For rhizosphere soil sampling, three equidistant points were located around the root system of each selected tree. At each point, the soil was dug to a depth of $20 \mathrm{~cm}$ to locate the roots, and then the soil that remained attached to the roots after mild mechanical disturbance was gently brushed with a sterile soft-bristled paintbrush (Philippot et al. 2013). In total, 15 points from five trees were mixed into one rhizosphere soil sample from each plot. The distance between sampling points and individual trees was approximately $1.5 \mathrm{~m}$. At the same time, bulk soil samples were collected from each plot. After the litter layer was removed, nine soil cores were collected using a soil auger ( $5 \mathrm{~cm}$ in diameter) along an S-shaped pattern and then mixed into one bulk soil sample from each plot. A total of 18 samples (three plots $\times$ three stand ages $\times$ two soil compartments) were collected. All soil samples were sieved $(2 \mathrm{~mm})$ and divided into two portions. One portion was stored at $-80^{\circ} \mathrm{C}$ for DNA analysis. The other portion was air dried for soil property analyses. 


\subsection{Soil property analyses}

Soil $\mathrm{pH}$ was measured in 1:2.5 (soil/water, $\mathrm{w} / \mathrm{v}$ ) ratio suspensions using a $\mathrm{pH}$ electrode. The soil moisture content (SMC) was measured by oven-drying $10 \mathrm{~g}$ of fresh soil at $105^{\circ} \mathrm{C}$ for $48 \mathrm{~h}$. Soil organic carbon (SOC) was measured via the potassium dichromate oxidation method. Total nitrogen (TN) was measured by the Kjeldahl method (Bremner and Mulvaney 1982). Total phosphorus (TP) and available phosphorus (AP) were measured by the molybdenum blue method after extraction with $\mathrm{H}_{2} \mathrm{SO}_{4}-\mathrm{HClO}_{4}$ and sodium bicarbonate, respectively (Olsen and Sommers 1982). Nitrate nitrogen $\left(\mathrm{NO}_{3}{ }^{-}{ }^{-} \mathrm{N}\right)$ and ammonium nitrogen $\left(\mathrm{NH}_{4}{ }^{+} \mathrm{N}\right)$ were measured by a continuous flow autoanalyzer (AA3, Germany) after extraction with $2 \mathrm{M} \mathrm{KCl}$ (Zhang et al. 2021).

\subsection{DNA extraction and Illumina sequencing}

Soil total DNA was extracted by a Fast DNA spin kit for soil (MP Biomedicals, Cleveland, USA). A NanoDrop 2000 spectrophotometer (NanoDrop Technologies, Wilmington, North Carolina, USA) and 1.2\% agarose gel electrophoresis were used to assess the quantity and quality of DNA. The primer pairs 338F/806R (Muyzer et al. 1993) and ITS 5F/ITS 1R (Ji et al. 2021) were used to amplify the bacterial 16S rRNA gene and fungal ITS gene, respectively. PCR was performed in a volume of $25 \mu \mathrm{L}$ containing $5 \mu \mathrm{L}$ GC buffer (5x), $5 \mu \mathrm{L}$ reaction buffer $(5 \times), 1 \mu \mathrm{L}$ forward primer $(10 \mu \mathrm{M}), 1 \mu \mathrm{L}$ reverse primer $(10 \mu \mathrm{M}), 2 \mu \mathrm{L}$ dNTPs $(2.5 \mathrm{mM}), 2 \mu \mathrm{L}$ DNA template, $0.25 \mu \mathrm{L}$ Q5 High-Fidelity DNA Polymerase $\left(5 \mathrm{ULL}^{-1}\right)$, and $8.75 \mu \mathrm{L}$ $\mathrm{ddH}_{2} \mathrm{O}$. The reaction conditions were as follows: 2 min of initial denaturation at $98^{\circ} \mathrm{C}, 25$ cycles of $15 \mathrm{~s}$ at $98^{\circ} \mathrm{C}, 30 \mathrm{~s}$ at $55^{\circ} \mathrm{C}$, and $30 \mathrm{~s}$ at $72^{\circ} \mathrm{C}$, and a final elongation for $5 \mathrm{~min}$ at $72^{\circ} \mathrm{C}$. The purified PCR amplicons were sequenced on a paired 250-bp Illumina MiSeq PE 250 platform (Illumina Corporation, USA).

Microbial raw sequences were analyzed using QIIME 2 2019.4 (Bolyen et al. 2019). With the use of the DADA2 pipeline, sequences were quality filtered, denoised, and merged, and the chimeras were removed (Callahan et al. 2016). Nonsingleton amplicon sequence variants (ASVs) were used to construct the phylogenetic tree. Taxonomic classification of ASVs was assigned using the SILVA (release 132, http://www.arb-silva.de) and UNITE (release 8.0, https://unite.ut.ee) databases for bacteria and fungi, respectively. A total of 91906 and 79700 sequences per sample of bacteria and fungi were generated after rarefication.

\subsection{Co-occurrence network analysis}

To reveal species coexistence across the chronosequence and soil compartment, co-occurrence networks of bacteria and fungi were constructed based on Sparse Correlations for Compositional data (SparCC). According to a previous method of combining samples in data analysis (Qiu et al. 2021; Zheng et al. 2021; Wang et al. 2022), six samples (combining bulk and rhizosphere samples) were used in cooccurrence networks of each chronosequence, and nine samples (combining samples of three stand ages) were contained in co-occurrence networks of different soil compartments. ASVs with average relative abundances greater than $0.05 \%$ and that occurred in more than $50 \%$ of samples in each corresponding subdataset were selected (Jiao et al. 2016). The correlations of SparCC $<0.7$ and $>-0.7$ 
and $P>0.01$ were removed. To further describe the topological properties of networks, a series of indexes (e.g., average degree, average path length, network diameter, graph density, clustering coefficient, and modularity) were calculated using the 'igraph' package in R (https://www.R-project.org/). The networks were visualized using the Gephi platform (https://gephi.org/).

In addition, according to the within-module connectivity $(Z i)$ and among-module connectivity $(P I)$, the nodes were divided into four categories: (1) network hubs (highly connected within the entire network, Zi > 2.5; $P i>0.62$ ); (2) module hubs (high connectivity within a module, $Z i>2.5$; $P i<0.62$ ); (3) connectors (link modules, $Z i<2.5 ; P i>0.62$ ); and (4) peripherals (less connectivity with other species, $Z i<2.5 ; P i<0.62$ ) (Deng et al. 2012; Poudel et al. 2016). Nodes belonging to network hubs, module hubs and connectors were defined as the keystone species owing to their crucial roles in networks (Guimera and Amaral 2005; Toju et al. 2018).

\subsection{Community assembly analysis}

The weighted $\beta$ nearest taxon index ( $\beta N T I)$ and Bray-Curtis-based Raup-Crick $\left(\mathrm{RC}_{\text {bray }}\right)$ were used to evaluate the assembly processes of microbial communities by a null model approach (Stegen et al. 2013). The $\beta N T I$ was calculated by determining the standard deviation between observed data and the null distribution of phylogenetic $\beta$-diversity metrics using the "picant" package in $\mathrm{R}$. The $\mathrm{RC}_{\text {bray }}$ value was quantified by estimating the standard deviation between the empirical data and the null distribution of taxonomic $\beta$-diversity metrics. The combination of $\beta \mathrm{NTI}$ and $\mathrm{RC}_{\text {bray }}$ was used to quantify the relative importance of deterministic (e.g., heterogeneous selection and homogeneous selection) and stochastic processes (e.g., dispersal limitation, homogenizing dispersal and drift). $\beta \mathrm{NTI}>2$ or $<-2$ represent heterogeneous selection or homogeneous selection, respectively. $|\beta N T| \mid<2$ with $\mathrm{RC}_{\text {bray }}>0.95$ or $\mathrm{R}_{\text {Cbray }}<$ -0.95 represent the contribution of dispersal limitation or homogenizing dispersal, respectively, and I $\beta N T I \mid<2$ with $\left|R C_{\text {bray }}\right|<0.95$ represents the contribution of drift (Stegen et al. 2013). The same method of combining soil samples with co-occurrence network analysis was used in community assembly analysis.

The neutral model was further used to determine the effects of stochastic processes on community assembly (Sloan et al. 2006). This model predicts the relationship between the frequency of observed species occurring in given localities and their abundance distribution in the metacommunity. The migration rate $(\mathrm{m})$ represents the probability that an individual locally lost by chance would be replaced by dispersal from the metacommunity. A higher $m$ value indicates that the microbial community is less restricted by dispersal. Levin's niche breadth index was calculated to help illustrate the patterns of deterministic processes and stochastic processes and their contribution to the microbial community under specialized habitats. A wider niche breadth indicates a microbial group with higher metabolic flexibility at the community level (Pandit et al. 2009). The "stats4" and "hmisc" packages in R were employed to carry out neutral model analysis, and the "spaa" package in R was used to calculate the niche breadth.

\subsection{Statistical analysis}


One-way analysis of variance (ANOVA) and $t$-tests were used to estimate the differences in the soil physicochemical properties, microbial alpha diversity, and niche breadth along the chronosequence and between the soil compartments, respectively. Two-way ANOVA was used to estimate the effects of the chronosequence and soil compartment on the soil physicochemical properties and microbial alpha diversity. Spearman's rank analysis was used to estimate the correlations of the soil physicochemical properties with dominant microbial taxa and alpha diversity. One- and two-way ANOVAs, $t$-tests and Spearman's rank analysis were conducted using SPSS 22.0 software. Principal coordinate analysis (PCOA) and two-way permutation multivariate ANOVA (PERMANOVA) with 999 permutations were used to determine the difference in the microbial community structure across the chronosequence and between the soil compartments using the "cmdscale" and "adonis" functions of the "vegan" package in R. Timedecay relationships (TDRs) of community similarity versus time in the bulk soil and rhizosphere were performed by fitting a linear model based on the community similarity distance (1-Bray-Curtis distance) and pairwise temporal interval. Mantel tests were used to unravel the relationship between soil physicochemical properties and microbial community composition, keystone species composition and $\beta N T I$. Furthermore, multiple regression on distance matrices (MRM) analysis was performed to understand which soil variables were associated with the keystone species composition of bacteria and fungi in the rhizosphere soil using the 'MRM' function of the "ecodist" package in R.

\section{Results}

\subsection{Soil properties}

Most of the soil physiochemical properties showed significant differences between the rhizosphere and bulk soil along the chronosequence (Table S2). The contents of SOC, SMC and TN increased gradually along the chronosequence and peaked in the 60-year-old plantation. However, soil pH showed an opposite trend. The SOC, AP, and C:N ratios were higher in the rhizosphere soil than in the bulk soil. Additionally, compared to the bulk soil, the $\mathrm{pH}$ in the rhizosphere soil was lower and more stable. Twoway ANOVAs indicated that the interaction between the chronosequence and soil compartment was significant for soil $\mathrm{pH}, \mathrm{TN}$, and $\mathrm{NO}_{3}{ }^{-}-\mathrm{N}$.

\subsection{Microbial community composition and diversity}

In total, 62771 bacterial ASVs and 6906 fungal ASVs were obtained. Across all samples, eight bacterial phyla/classes, namely, Acidobacteria (21.66\%), Actinobacteria (19.21\%), Gammaproteobacteria (11.81\%), Chloroflexi (10.60\%), Alphaproteobacteria (9.32\%), Gemmatimonadetes (7.96\%), Deltaproteobacteria (5.37\%) and Rokubacteria (4.62\%), dominated the bacterial communities (Fig. S1). The most abundant fungal class was Agaricomycetes (65.11\%), followed by Sordariomycetes (3.60\%), Pezizomycetes (3.44\%), Archaeorhizomycetes (1.84\%), Mortierellomycetes (1.52\%), and Leotiomycetes (1.29\%) (Fig. S1). The relative abundance of Alphaproteobacteria and Gammaproteobacteria in the rhizosphere soil increased gradually along the chronosequence and was significantly higher than that in the bulk soil. The abundance of all of the detected fungi except Agaricomycetes and Sordariomycetes in the bulk soil 
decreased along the chronosequence. Pezizomycetes, Mortierellomycetes, and Eurotiomycetes were more abundant in the rhizosphere soil than in bulk soil from 30 to 60 years.

For bacteria, the alpha diversity (Shannon and Chao1) showed no significant differences along the chronosequence but significantly $(P<0.05)$ increased from the bulk soil to the rhizosphere. The chronosequence and soil compartment had no effects on the Shannon diversity and richness of the fungal communities (Table S3).

PCoA showed that the bacterial and fungal compositions were clearly separated among the three forest ages (Fig. 1). The first two axes explained $41.21 \%$ and $41.62 \%$ of the total variation in the soil bacterial and fungal communities, respectively. Two-way permutational multivariate analysis of variance (PERMANOVA) revealed that the chronosequence had a stronger influence than the soil compartment on the bacterial and fungal community structures (Fig. 1). The Mantel tests indicated that the bacterial community structure had significant correlations with SMC, SOC and AP. SMC was the key factor correlated with the fungal community structure (Table S4). The dominant bacterial taxa and diversity appeared to have a stronger interrelationship than fungi with the soil properties (Table S5).

Significant TDRs were found for the soil bacterial community in the different soil compartments (Fig. 2). The slopes of the bacterial communities in the rhizosphere soil were significantly steeper than those in the bulk soil, revealing rapid community turnover in the rhizosphere soil. However, a significant TDR was observed for fungal communities only in the rhizosphere soil, which suggested that the turnover rates of fungal communities changed dramatically along the chronosequence.

\subsection{Microbial community networks}

Multiple network topological properties revealed that the co-occurrence patterns of the bacterial and fungal networks changed constantly along the chronosequence (Fig. 3 and Table S6). All networks showed strong power-law distributions of degrees, indicating typical scale-free degree characteristics (Fig. S2). For bacteria, the network diameter and average path length decreased along the chronosequence, while the number of edges, graph density, average degree, and clustering coefficient tended to increase, suggesting a more connected network structure with stand age (Table S6). In addition, the positive correlations in the bacterial network in 60 -year-old plantations increased by $9.98 \%$ and $12.55 \%$ compared with those in 30 -year-old and 15 -year-old plantations, respectively. This result indicated that the conflicting interactions (the competition among the bacterial species) decreased gradually along the chronosequence (Table S6). For fungi, the clustering coefficient, graph density, and average degree increased from 15 years to 30 years and later decreased at 60 years. The trends of the positive correlations were the opposite of those found in bacterial networks, indicating that the increase in stand age might lead to more conflicting interactions (Table S6). In addition, the bacterial networks were similar between the rhizosphere and bulk soil. However, fungal networks were different between the different soil compartments. The rhizosphere soil had higher numbers of nodes (86) and edges (188) and a higher average degree (4.37) than bulk soil, suggesting more complex relationships among the fungal species. 
There were a total of 321 connectors, 13 module hubs (network hub ASVs), and 2 network hubs identified in the bacterial networks (Fig. S3 and Table S7). However, the numbers and their taxonomic affiliations differed among the three stand ages. The greatest number of connectors was observed in the 15-year-old plantation, which mainly belonged to Acidobacteria, Actinobacteria, Chloroflexi, and Gammaproteobacteria. There were three module hubs belonging to Alphaproteobacteria (1 ASV) and Chloroflexi (2 ASVs). In the 30-year-old plantation, 83 connectors and 5 module hubs were detected among various taxonomic groups. The connectors were mainly related to Acidobacteria and Gammaproteobacteria. Module hubs were related to Acidobacteria (1 ASV), Actinobacteria (2 ASVs) and Alphaproteobacteria (2 ASVs). In the 60-year-old plantation, the 103 connectors were mainly assigned to Acidobacteria, Gemmatimonadetes, and Rokubacteria. The 5 module hubs were assigned to Actinobacteria (1 ASV), Chloroflexi (1 ASV), Deltaproteobacteria (1 ASV) and Gammaproteobacteria (2 ASVs). The only 2 network hubs detected at this site belonged to Actinobacteria and Alphaproteobacteria. In addition, the number of connectors increased from the rhizosphere (63) to the bulk soil (77). No module hubs or network hubs were identified in the rhizosphere soil. In the fungal networks, the number of connectors decreased gradually with stand age (Fig. S3). A higher number of connectors was observed in the rhizosphere (39) than in the bulk soil (32). These connectors originated from a variety of taxonomic groups and were mainly related to Saccharomycetes, Sordariomycetes, Agaricomycetes, and Mortierellomycota (Table S7). A module hub (1 ASV) was identified only at the 30-year-old site, which was related to Tremellomycetes. No network hub was detected in the fungal networks.

The correlation between soil properties and keystone species suggested that bacterial keystone species in the rhizosphere had significantly positive correlations with TP and $\mathrm{NO}_{3}{ }^{-}-\mathrm{N}$, and fungal keystone species in the rhizosphere were positively and significantly correlated with SOC, TN, and TP (Table S8). The MRM models revealed that TP and $\mathrm{NO}_{3}{ }^{-} \mathrm{N}$ had strong effects on bacterial keystone species in the rhizosphere, and fungal keystone species in the rhizosphere were strongly affected by $\mathrm{SMC}, \mathrm{TN}, \mathrm{TP}$, and $\mathrm{NO}_{3}{ }^{-}-\mathrm{N}(\mathrm{Table}$ 1). 
Table 1

Multiple regression with distance matrices (MRM) to estimate the contribution of soil properties on the rhizospheric keystone species composition.

\begin{tabular}{|c|c|c|}
\hline \multirow[t]{2}{*}{ Soil properties } & $\begin{array}{l}\text { Bacterial keystone taxa } \\
\mathrm{R}^{2}=0.506\end{array}$ & $\begin{array}{l}\text { Fungal keystone taxa } \\
\mathrm{R}^{2}=0.642\end{array}$ \\
\hline & $P<0.05$ & $P<0.01$ \\
\hline $\mathrm{pH}$ & -0.240 & 0.484 \\
\hline SMC & ND & $-0.064^{*}$ \\
\hline soc & 0.003 & 0.009 \\
\hline TN & -0.013 & $0.220 *$ \\
\hline TP & $0.210 *$ & $0.590 *$ \\
\hline $\mathrm{NO}_{3}^{-}-\mathrm{N}$ & $0.032^{*}$ & $0.150 *$ \\
\hline $\mathrm{NH}_{4}^{+}-\mathrm{N}$ & -0.031 & ND \\
\hline AP & ND & ND \\
\hline $\mathrm{C} / \mathrm{N}$ & ND & -0.003 \\
\hline Note. ND, not d & rmined. * $P<0.05, * * P<$ & $0.01, \star \star \star * P<0.001$ \\
\hline
\end{tabular}

\subsection{Microbial assembly processes}

Figure 4 shows that stochastic processes, especially dispersal limitation, dominated both bacterial and fungal community assembly. However, the relative contribution of stochastic and deterministic processes in explaining the variation in microbial community assembly changed with stand age. The relative importance of dispersal limitation decreased by $33.33 \%$ from the 15 -year-old to the 30 -year-old plantation and then increased by $26.67 \%$ for the bacterial community assembly, while the reverse trend was observed for the fungal community assembly. Regarding the soil compartment, dispersal limitation explained $55.56 \%$ of the variation in the bacterial community assembly in the rhizosphere soil, which was the same as that in the bulk soil. The contribution of dispersal limitation to the bacterial community assembly in the rhizosphere soil was the same as that in the bulk soil. However, dispersal limitation explained more of the variation in the fungal assembly patterns, increasing from $77.78 \%$ in the bulk soil to $88.89 \%$ in the rhizosphere soil. Homogeneous selection, homogenizing dispersal, drift, and heterogeneous selection slightly affected the assembly of the microbial community. In addition, $\beta N T I$ and soil properties had no significant correlation, indicating less environmental filtering in controlling microbial community assembly (Table S9). 
The migration rates of bacteria were lowest in the 30-year-old plantation, and fungi showed the opposite trend, indicating that the bacterial community was more limited and that the fungal community was less limited by dispersal in the 30-year-old plantation than in the 15- and 60-year-old plantations. In addition, the bacterial migration rates tended to be higher in the rhizosphere than in the bulk soil. The fungal migration rates were contrary to the bacterial migration rates, which suggested that the fungal community was more limited by dispersal in the rhizosphere than in the bulk soil (Fig. 5). Similarly, the habitat niche breadth of bacteria and fungi exhibited the same trends as the migration rates in the different plantations and soil compartments.

\section{Discussion}

\subsection{Microbial community diversity and structure}

Our data showed that there was no significant difference in the alpha diversity of the soil microbial community during the development of the Pinus tabulaeformis plantations. Generally, soil microbial diversity and richness increase with vegetation succession due to the increase in understory vegetation composition and diversity (Xu et al. 2020; Zhong et al. 2020). However, in the vegetation succession process, the changes in the microbial community lag behind those in the vegetation and soil (Niu et al. 2007). The microbial community has high resilience and resistance to environmental disturbance (Griffiths and Philippot 2012). Furthermore, the dominant trees determine the soil microbial community composition (Urbanová et al. 2015). The microbial community structure remained relatively stable throughout the three stand ages. Therefore, the alpha diversity of the soil microbial communities did not change.

Soil properties regulated the dominant groups in the soil bacterial and fungal communities and thus led to differences in the soil microbial community composition (Liu et al. 2018). In the present study, Proteobacteria, Acidobacteria, Actinobacteria and Chloroflexi were the dominant bacterial phyla at all experimental sites. The relative abundance of Proteobacteria increased gradually with stand age and peaked in the 60-year-old plantation. Proteobacteria are defined as copiotrophic bacteria that have high nutritional requirements. Actinobacteria belong to the oligotrophic group and are adapted to growth in stressful environments (Zhang et al. 2021). The development of Pinus tabulaeformis plantations was favorable for labile substrate input and soil nutrient accumulation and thus promoted the growth of copiotrophic bacteria. The decrease in the relative abundance of Actinobacteria might also be demonstrated from the opposite perspective. Basidiomycota and Ascomycota dominated fungal communities in the Pinus tabulaeformis plantation. The relative abundance of Basidiomycota in the 60year-old plantation increased by $27.80 \%$ compared to that in the 15 -year-old plantation. This might be because Basidiomycota are responsible for the decomposition of lignin and aromatic compounds in a forest ecological system (Dang et al. 2018). The plant litter source and amount increase with stand age, and the needles of Pinus tabulaeformis are rich in lignin and cellulose, which might be degraded by Basidiomycota. In addition, Pinus tabulaeformis is an ectomycorrhizal tree species. Most ectomycorrhizal fungi belong to Basidiomycota, which increase the availability of water and nutrients (Varenius et al. 
2016). The relative abundance of Ascomycota decreased with stand age. Recent studies have revealed that Ascomycota thrive under oligotrophic conditions, especially on low carbon substrates (Dang et al. 2018). Therefore, the higher abundance of Ascomycota revealed that the fungal communities adapted to poor soil nutrient conditions. The variation in Basidiomycota and Ascomycota with plantation development indicated that the growth of vegetation changed the soil nutrient conditions. In addition, plant roots select the specific microorganisms that colonize the rhizosphere to enhance nutrient acquisition and protect against pathogenic bacteria (Dennis et al. 2010). In the present study, the decrease in soil available phosphorus with stand age indicated that the requirement for phosphorus continues to increase in plants as plantation development. It was reported that Alphaproteobacteria might produce and secrete phosphomonoesterase by regulating the expression of the phoD gene and thus improve phosphorus availability (Mise et al. 2018). Actinobacteria are also crucial for phosphorus solubilization (Sahu et al. 2007). The higher relative abundance of Alphaproteobacteria and Actinobacteria in the rhizosphere soil may reflect the plant demand, and these bacteria may facilitate plant phosphorus absorption.

The temporal turnover of soil microbial communities is a vital indicator of the successional dynamics of biological communities owing to its tight association with ecological functions (Zhang et al. 2019). Our results showed that the bacterial and fungal succession rates in the rhizosphere were higher than those in the bulk soil. This finding supported the first hypothesis that temporal turnover decreased from the rhizosphere soil to the bulk soil. A possible reason might be that plentiful carbon substrates are derived from carbon fixed by photosynthesis, root exudates, and plant residue decomposition in the rhizosphere (Song et al. 2019). Consequently, the microbial activity, turnover, and copiotrophic bacteria (e.g., Proteobacteria) increased significantly in this zone. Furthermore, a series of specific bacterial and fungal that are responsible for improving nutrient absorption and protecting against pathogens. The extensive changes in the temporary turnover of the soil microbial community depended on variations in plant and soil nutrient status during plant growth and development.

\subsection{Microbial species co-occurrence networks and keystone species}

Co-occurrence network analysis reflects the assembly principles and interspecies relationships of soil microbial communities and thereby provides a greater understanding of the relationships between ecosystem complexity and stability (Zhu et al. 2020). In the present study, the complexity of the bacterial networks tended to increase markedly with increasing stand age (Fig. 3 and Table S6), which led to higher community stability. Furthermore, the bacterial network in the 60 -year-old plantation had more positive correlations than those in the 15- and 30-year-old plantations (Table S6), revealing that the competition among bacterial species decreased gradually during plantation development. This pattern might be attributed to the increase in resource availability and niche availability across the plantation chronosequence (Fan et al. 2018b). However, the fungal network structure showed no clear age-related trends from 15 years to 60 years (Fig. 3 and Table S6), indicating that soil environmental heterogeneity had minor effects on the fungal community dynamics in our study. In contrast, fungal networks in the 
rhizosphere soil had more nodes and edges than those in the bulk soil, suggesting an increase in network complexity. Abundant ectomycorrhizal (ECM) fungi form mutualistic symbioses with Pinus tabulaeformis and are regarded as key organisms involved in plant nutrient and carbon cycling (Wang et al. 2021), driving fungal communities to enhance their interspecific communication in the form of complex cooccurrence networks during plantation development.

Generally, keystone species are connectors, module hubs, and network hubs that play critical roles in network structure and regulate important ecosystem functions (e.g., soil organic matter metabolism, nitrogen metabolic pathway) within the whole community (Xun et al. 2021). Variations in keystone species might reflect variations in the interspecies relationship to some extent, thus impacting soil nutrient cycling. In the present study, the keystone species changed with stand age and differed in the rhizosphere and bulk soils due to the interactions between vegetation development and soil properties (Table S9). The specific functions of the keystone species also changed. The bacterial network hub Actinobacteria has the ability to decompose a range of recalcitrant organic substances (e.g., cellulose, organic acids, polysaccharides) (de Menezes et al. 2015) and to produce antibiotics (e.g., streptomycin, aureomycin, and terramycin) (Dhanasekaran and Jiang 2016). Alphaproteobacteria mainly include Rhizobiales, which supply phytohormones and a variety of nutrients to plants and perform nitrogen fixation through symbiosis with their host (Erlacher et al. 2015). The bacterial module hub Chloroflexi, composed of phototrophic bacteria, has anoxygenic photosynthetic activity (Hanada 2014). This phylum can also ferment carbohydrates and degrade some complex organic polymeric compounds (Speirs et al. 2015). Deltaproteobacteria and Gammaproteobacteria belong to Proteobacteria, which grow quickly by utilizing carbon substrates derived from roots (Fan et al. 2018b). The bacterial connector Gemmatimonadetes has been reported to have chlorophyll-based reaction centers that might be responsible for the synthesis of carbon (Zeng et al. 2014). Rokubacteria participate in the TCA cycle, glycolysis, and complex transport and thus play important roles in carbon cycling (Becraft et al. 2017). The fungal module hub Tremellomycetes can effectively resist drought by cryptobiosis (Esser 2014). The fungal connectors belong to Dothideomycetes (e.g., Saccharomycetes and Sordariomycetes) (Luo et al. 2019). Agaricomycetes (Sterkenburg et al. 2018) and Mortierellomycota (Loit et al. 2020) have the capacity to enhance nutrient availability by degrading cellulose, promoting nutrient release from litter, resisting disease, and cooperating with other species. In summary, during the development of plantations, these keystone species had a variety of metabolic functions and thus affected the interspecies relationships in the whole community.

\subsection{Microbial assembly process}

Revealing the mechanisms mediating microbial community assembly is a crucial topic in microbial ecology (Zhou and Ning 2017). It is important to clarify how assembly processes respond to environmental factors, at both temporal and spatial scales. In our study, stochastic processes were vitally important for microbial assembly during Pinus tabulaeformis plantation development in both the rhizosphere soil and bulk soil, indicating weak selection from environmental variation. One possible explanation is that the increase in soil nutrients (e.g., SOC and TN) (Table S2) provided diverse and 
alternative nutrient resources for taxa, which widened the habitat niche breadth and thus weakened environmental filtering (Shu et al. 2021). Additionally, Chen et al. (2020) found that body size might be used as an important indicator to evaluate the dispersal capacity of microorganisms. According to the "size plasticity" (Farjalla et al. 2012) and "size dispersal" hypotheses (Shurin et al. 2009), bacteria might be less niche limited and thus dispersal limited than fungi. In the present study, the fungal community in the rhizosphere soil was more affected by dispersal limitation than the bacterial community, supporting these hypotheses. However, the bacterial community had lower dispersal limitation in the 30-year-old plantation, which was attributed to the selectivity of the habitat niche (Chen et al. 2020). When bacteria disperse to a new niche, the occupancy of the niche is restricted, and the niche is not colonized by all individuals, revealing limited dispersion.

\section{Conclusions}

Our results showed that the soil microbial communities in the rhizosphere differed significantly from those in the bulk soil during Pinus tabulaeformis plantation development. The influences of afforestation age on the soil microbial communities were greater than those of the soil compartments. The complexity and connection of the bacterial network structure increased with stand age but showed no clear variation between the soil compartments. The complexity of the fungal network structure did not show a clear agerelated trend but increased from the bulk soil to the rhizosphere. The stochastic process and dispersal limitation played an essential role in the microbial community assembly along the chronosequence regardless of the soil compartment. Bacterial communities with a wider niche breadth were less dispersal limited than fungal communities. These results indicated that plantation development might enhance forest ecosystem stability, and thus reduce the influence of environmental filtering on soil microbial assembly. Our results highlighted the dynamics of the microbial assembly process during afforestation. Further studies should focus on the linkage between the assembly of the soil microbial community and its functional properties, which will be critical for understanding the mechanism by which soil microbial communities mediate ecosystem function.

\section{Declarations}

\section{CRediT authorship contribution statement}

Conceptualization: Ying Wang, Liguo Dong, Xuan Yu. Data curation: Ying Wang, Min Zhang, Xuan Yu. Formal analysis: Xiaoxiong Bai, Jiawen Zhang, Xuan Yu. Funding acquisition: Xuan Yu. Investigation: Ying Wang, Min Zhang, Jiawen Zhang, Xiaoxiong Bai, Xuan Yu. Methodology: Ying Wang, Xuan Yu, Liguo Dong. Project administration: Xuan Yu. Software: Ying Wang, Min Zhang. Supervision: Jiawen Zhang, Liguo Dong. Visualization: Ying Wang, Liguo Dong, Min Zhang. Writing - original draft: Ying Wang, Xuan Yu. Writing - review \& editing: Ying Wang, Liguo Dong, Min Zhang, Xuan Yu.

\section{Declaration of competing interest}


The authors declare that they have no known competing financial interests or personal relationships that could have appeared to influence the work reported in this paper.

\section{Acknowledgements}

We thank Guanzhuang State-owned Ecology Experimental Forest Farm for assistance with soil samples collecting and providing basic data of sample sites.

\section{Funding}

This study was financially supported by the National Natural Science Foundation of China (31670629), National Key Research and Development Program of China (2016YFC0501706-1), China Postdoctoral Science Foundation (2016M60082), Tang Scholar Program of Northwest A\&F University, and Fundamental Research Funds for the Central Universities (2452018345).

\section{References}

1. Bahram M, Kõljalg U, Kohout P, Mirshahvaladi S, Tedersoo L (2013) Ectomycorrhizal fungi of exotic pine plantations in relation to native host trees in Iran: Evidence of host range expansion by local symbionts to distantly related host taxa. Mycorrhiza 23:11-19. https://doi.org/10.1007/s00572-0120445-z

2. Bremner JM, Mulvaney CS (1982) Nitrogen-total. In: Page AL, Miller RH, (Eds.). Methods of soil analysis, Chemical and microbial properties. Agronomy Society of America, Agronomy Monography 9, Madidon, Wisconsin, pp. 595-624.

3. Becraft ED, Woyke T, Jarett J, Ivanova N, Godoy-Vitorino F, Poulton N, Brown JM, Brown J, Lau MCY, Onstott T, Eisen JA, Moser D, Stepanauskas R (2017) Rokubacteria: genomic giants among the uncultured bacterial phyla. Front Microbiol 8:22-64. https://doi.org/10.3389/fmicb.2017.02264

4. Bolyen E, Rideout JR, Dillon MR, Bokulich NA, Abnet CC, Al-Ghalith GA, Alexander H, Alm EJ, ... Caporaso JG (2019) Reproducible, interactive, scalable and extensible microbiome data science using QIIME 2. Nat Biotechnol 37:1091-1091. https://doi.org/10.1038/s41587-019-0252-6

5. Callahan BJ, McMurdie PJ, Rosen MJ, Han AW, Johnson AJA, Holmes SP (2016) DADA2: Highresolution sample inference from Illumina amplicon data. Nat Methods 13:581-583. https://doi.org/10.1038/Nmeth.3869

6. Canarini A, Kaiser C, Merchant A, Richter A, Wanek W (2019) Root exudation of primary metabolites: mechanisms and their roles in plant responses to environmental stimuli. Front Plant Sci 10:1-19. https://doi.org/10.3389/fpls.2019.00157

7. Chase JM (2010) Stochastic community assembly causes higher biodiversity in more productive environments. Science 328:1388-1391. https://doi.org/10.1126/science.1187820

8. Chase TJ, Pratchett MS, Walker SPW, Hoogenboom MO (2014) Small-scale environmental variation influences whether coral-dwelling fish promote or impede coral growth. Oecologia 176(4):1009- 
1022. https://doi.org/10.1007/s00442-014-3065-9

9. Chen WM, Jiao S, Li QP, Du NN (2020) Disperse limitation relative to environmental filtering governs the vertical small-scale assembly of soil microbiomes during restoration. J Appl Ecol 57:402-412. https://doi.org/10.1111/1365-2664.13533

10. Dang P, Gao Y, Liu JL, Yu SC, Zhao Z (2018) Effects of thinning intensity on understory vegetation and soil microbial communities of a mature Chinese pine plantation in the Loess Plateau. Sci Total Environ 630:171-180. https://doi.org/10.1016/j.scitotenv.2018.02.197

11. Deng Y, Jiang YH, Yang YF, He ZL, Luo F, Zhou JZ (2012) Molecular ecological network analyses. BMC Bioinformatics 13:1-20. https://doi.org/10.1186/1471-2105-13-113

12. Dennis PG, Miller AJ, Hirsch PR (2010) Are root exudates more important than other sources of rhizodeposits in structuring rhizosphere bacterial communities? FEMS Microbiol Ecol 72(3):313327. https://doi.org/10.1111/j.1574-6941.2010.00860.x

13. de Menezes AB, Prendergast-Miller MT, Poonpatana P, Farrell M, Bissett A, Macdonald LM, Toscas P, Richardson AE, Thrall PH (2015) C/N ratio drives soil Actinobacterial cellobiohydrolase Gene diversity. Appl Environ Microb 81(9):3016-3028. https://doi.org/10.1128/AEM.00067-15

14. Dhanasekaran D, Jiang Y (2016) Actinobacteria - basics and biotechnological applications. In: Anandan R, Dharumadurai D (Eds.), An introduction to Actinobacteria. Springer, New York, pp. 3-37.

15. Dini-Andreote F, Stegen JC, van Elsas JD, Salles JF (2015) Disentangling mechanisms that mediate the balance between stochastic and deterministic processes in microbial succession. PNAs 112:1326-1332. https://doi.org/10.1073/pnas.1414261112

16. Dobrovol'skaya TG, Zvyagintsev DG, Chernov IY, Golovchenko AV, Zenova GM, Lysak LV, Manucharova NA, Marfenina OE, Polyanskaya LM, Stepanov AL, Umarov MM (2015) The role of microorganisms in the ecological functions of soils. Eurasian Soil Sci 48(9):959-967. https://doi.org/10.1134/S1064229315090033

17. Erlacher A, Cernava T, Cardinale T, Soh J, Sensen CW, Grube M, Berg G (2015) Rhizobiales as functional and endosymbionic members in the lichen symbiosis of Lobaria pulmonaria L. Front Microbiol 6:1-9. https://doi.org/10.3389/fmicb.2015.00053

18. Esser K (2014) The Mycota: A comprehensive treatise on fungi as experimental systems for basic and applied research. In: Weiss M, Bauer R (Eds.), Tremellomycetes and related groups. Springer, Berlin Heidelberg, pp. 331-449.

19. Fan KK, Weisenhorn P, Gilbert JA, Shi Y, Bai Y, Chu HY (2018a) Soil pH correlates with the cooccurrence and assemblage process of diazotrophic communities in rhizosphere and bulk soils of wheat fields. Soil Biol Biochem 121:185-192. https://doi.org/10.1016/j.soilbio.2018.03.017

20. Fan KK, Weisenhorn P, Gilbert JA, Chu HY (2018b) Wheat rhizosphere harbors a less complex and more stable microbial co-occurrence pattern than bulk soil. Soil Biol Biochem 125:251-260. https://doi.org/10.1016/j.soilbio.2018.07.022

21. Farjalla VF, Srivastava DS, Marino NAC, Azevedo FD, Dib V, Lopes PM, Esteves FA (2012) Ecological determinism increases with organism size. Ecology 93:1752-1759. 
https://doi.org/10.2307/23225239

22. Faust K, Raes J (2012) Microbial interactions: from networks to models. Nat Rev Microbiol 10(8):538-550. https://doi.org/10.1038/nrmicro2832

23. Goss-Souza D, Mendes LW, Borges CD, Rodrigues JLM, Tsai SM (2019) Amazon forest-to-agriculture conversion alters rhizosphere microbiome composition while functions are kept. FEMS Microbiol Ecol 95(3):1-13. https://doi.org/10.1093/femsec/fiz009

24. Griffiths BS, Philippot $L$ (2013) Insights into the resistance and resilience of the soil microbial community. FEMS Microbiol Rev 37:112-129. https://doi.org/10.1111/j.1574-6976.2012.00343.x

25. Guimera R, Amaral LAN (2005) Functional cartography of complex metabolic networks. Nature 433:895-900. https://doi.org/10.1038/nature03288

26. Guo YQ, Xu TQ, Cheng JM, Wei GH, Lin YB (2021) Above- and belowground biodiversity drives soil multifunctionality along a long-term grassland restoration chronosequence. Sci Total Environ 772:111. https://doi.org/10.1016/j.scitotenv.2021.145010

27. Hanada S (2014) The prokaryotes - other major lineages of bacteria and the archaea. In: Rosenberg E, DeLong EF (Eds.), The phylum Chloroflexi, the family Chloroflexaceae, and the related phototrophic families Oscillochloridaceae and Roseiflexaceae. Springer, Berlin Heidelberg, pp. 515-532.

28. Hartman K, Tringe SG (2019) Interactions between plants and soil shaping the root microbiome under abiotic stress. Biochem J 476(19):2705-2724. https://doi.org/10.1042/BCJ20180615

29. Hassani MA, Durán P, Hacquard S (2018) Microbial interactions within the plant holobiont. Microbiome 6:1-17. https://doi.org/10.1186/s40168-018-0445-0

30. Ji L, Nasir F, Tian L, Chang JJ, Sun Y, Zhang JF, Li XJ, Tian, CJ (2021) Outbreaks of root rot disease in different aged american ginseng plants are associated with field microbial dynamics. Front Microbiol 12:1-13. https://doi.org/10.3389/fmicb.2021.676880

31. Jiao S, Liu Z, Lin Y, Yang J, Chen W, Wei G (2016) Bacterial communities in oil contaminated soils: biogeography and co-occurrence patterns. Soil Biol Biochem 98:64-73. https://doi.org/10.1016/j.soilbio.2016.04.005

32. Khan N, Ali S, Shahid MA, Mustafa A, Sayyed RZ, Curá JA (2021) Insights into the interactions among roots, rhizosphere, and rhizobacteria for improving plant growth and tolerance to abiotic stresses: a review. Cells 10:1-19. https://doi.org/10.3390/cells10061551

33. Li H, Su JQ, Yang XR, Zhu YG (2019) Distinct rhizosphere effect on active and total bacterial communities in paddy soils. Sci Total Environ 649:422-430. https://doi.org/10.1016/j.scitotenv.2018.08.373

34. Liu JL, Vu NH, Shen Z, Dang P, Zhu HL, Zhao F, Zhao Z (2018) Response of the rhizosphere microbial community to fine root and soil parameters following Robinia pseudoacacia L. afforestation. Appl Soil Ecol 132:11-19. https://doi.org/10.1016/j.apsoil.2018.08.004

35. Liu L, Zhu K, Krause SMB, Li SP, Wang X, Zhang ZC, Shen MW, Yang QS, Lian JY, Wang XH, Ye WH, Zhang $J$ (2021) Changes in assembly processes of soil microbial communities during secondary 
succession in two subtropical forests. Soil Biol Biochem 154:1-7.

https://doi.org/10.1016/j.soilbio.2021.108144

36. Liu Y, Chen XT, Liu JX, Liu TT, Cheng JM, Wei GH, Lin YB (2019) Temporal and spatial succession and dynamics of soil fungal communities in restored grassland on the Loess Plateau in China. Land Degrad Dev 30:1273-1287. https://doi.org/10.1002/ldr.3289

37. Liu JS, Zhang X, Wang H, Hui XL, Wang ZH, Qiu WH (2018) Long-term nitrogen fertilization impacts soil fungal and bacterial community structures in a dryland soil of Loess Plateau in China. J Soils Sediment 18(4):1632-1640. https://doi.org/10.1007/s11368-017-1862-6

38. Loit K, Soonvald L, Astover A, Runno-Paurson E, Öpik M, Tedersoo L (2020) Temporal and cultvarspecific effects on potato root and rhizosphere fungal diversity. Agronomy 10:1-19. https://doi.org/10.20944/preprints202007.0218.v1

39. Luan L, Liang C, Chen LL, Wang HT, Xu QS, Jiang YJ, Sun B (2020) Coupling bacterial community assembly to microbial metabolism across soil profiles. mSystems 5:1-15.

https://doi.org/10.1128/mSystems.00298-20

40. Luo ZL, Hyde KD, Liu JK, Maharachchikumbura SSN, Jeewon R, Bao DF, Bhat DJ, Lin CG, Li WL, Yang J, Liu NG, Lu YZ, Jayawardena RS, Li JF, Su HY (2019) Freshwater Sordariomycetes. Fungal Divers 99:451-660. https://doi.org/10.1007/s13225-019-00438-1

41. Mendes LW, Kuramae EE, Navarrete AA, van Veen JA, Tsai SM (2014) Taxonomical and functional microbial community selection in soybean rhizosphere. ISME J 8(8):1577-1587. https://doi.org/10.1038/ismej.2014.17

42. Meier IC, Tuckmantel T, Heitkotter J, Muller K, Preusser S, Wrobel TJ, Kandeler E, Marschner B, Leuschner C (2020) Root exudation of mature beech forests across a nutrient availability gradient: the role of root morphology and fungal activity. New Phytol 226(2):583594. https://doi.org/10.1111/nph.16389

43. Mise K, Fujita K, Kunito T, Senoo K, Otsuka S (2018) Phosphorus-mineralizing communities reflect nutrient-rich characteristics in Japanese Arable Andisols. Microbes Environ 33:282289. https://doi.org/10.1264/jsme2.ME18043

44. Muyzer G, De Waal EC, Uitterlinden AG (1993) Profiling of complex microbial populations by denaturing gradient gel electrophoresis analysis of polymerase chain reaction-amplified genes coding for 16S rRNA. Appl Environ Microb 59:695-700. https://doi.org/0.1128/aem.59.3.695 700.1993

45. Niu HB, Liu WX, Wan FH, Liu B (2007) An invasive aster (Ageratina adenophora) invades and dominates forest understories in China: altered soil microbial communities facilitate the invader and inhibit natives. Plant Soil 294:73-85. https://doi.org/10.1007/s11104-007-9230-8

46. Olsen SR, Sommers LE (1982) Phosphorus. In: Page AL, Miller RH (Eds.), Methods of soil analysis part 2 chemical and microbiological properties. American Society of Agronomy, Soil Science Society of America, Madison, pp. 403-430. 
47. Pandit SN, Kolasa J, Cottenie K (2009) Contrasts between habitat generalists and specialists: an empirical extension to the basic metacommunity framework. Ecology 90:2253-2262. https://doi.org/10.1890/08-0851.1

48. Pascale A, Proietti S, Pantelides IS, Stringlis IA (2020) Modulation of the root microbiome by plant molecules: the basis for targeted disease suppression and plant growth promotion. Front Plant Sci 10:1-23. https://doi.org/10.3389/fpls.2019.01741

49. Philippot L, Raaijmakers JM, Lemanceau P, van der Putten WH (2013) Going back to the roots: the microbial ecology of the rhizosphere. Nat Rev Microbiol 11:789-799. https://doi.org/10.1038/nrmicro3109

50. Poudel R, Jumpponen A, Schlatter DC, Paulitz TC, Gardener BBM, Kinkel LL, Garrett KA (2016) Microbiome networks: A systems framework for identifying candidate microbial assemblages for disease management. Phytopathology 106:1083-1096. https://doi.org/10.1094/Phyto-02-16-0058$\mathrm{Fi}$

51. Pugnaire FI, Morillo JA, Penuelas J, Reich PB, Bardgett RD, Gaxiola A, Wardle DA, van der Putten WH (2019) Climate change effects on plant-soil feedbacks and consequences for biodiversity and functioning of terrestrial ecosystems. Sci Adv 5(11):1-12. https://doi.org/10.1126/sciadv.aaz1834

52. Qiu LP, Zhang Q, Zhu HS, Reich PB, Banerjee S, van der Heijden MGA, Sadowsky MJ, Ishii S, Jia XX, Shao MG, Liu BY, Jiao H, Li HQ, Wei XR (2021) Erosion reduces soil microbial diversity, network complexity and multifunctionality. ISME J 15:2474-2489. https://doi.org/10.1038/s41396-02100913-1

53. Rüger L, Feng K, Dumack K, Freudenthal J, Chen Y, Sun RB, Wilson M, Yu P, Sun B, Deng Y, Hochholdinger $F$, Vetterlein D, Bonkowski M (2021) Assembly patterns of the rhizosphere microbiome along the longitudinal root axis of maize (Zea mays L.). Front Microbiol 12:1-14. https://doi.org/10.3389/fmicb.2021.614501

54. Sahu MK, Sivakumar K, Thangaradjou T, Kannan L (2007) Phosphate solubilizing actinomycetes in the estuarine environment: An inventory. J Environ Biol 28(4):795-798. https://doi.org/10.1007/9783-319-08216-5_6

55. Shu DT, Guo YQ, Zhang BG, Zhang CF, Van Nostrand JD, Lin YB, Zhou JZ, Wei GH (2021) Rare prokaryotic sub-communities dominant the complexity of ecological networks and soil multinutrient cycling during long-term secondary succession in China's Loess Plateau. Sci Total Environ 774:1-14. https://doi.org/10.1016/j.scitotenv.2021.145737

56. Shurin JB, Cottenie K, Hillebrand H (2009) Spatial autocorrelation and dispersal limitation in freshwater organisms. Oecologia 159:151-159. https://doi.org/10.1007/s00442-008-1174-z

57. Sloan WT, Lunn M, Woodcock S, Head IM, Nee S, Curtis TP (2006) Quantifying the roles of immigration and chance in shaping prokaryote community structure. Environ Microbiol 8:732-740. https://doi.org/10.1111/j.1462-2920.2005.00956.x

58. Song ZL, Liu GB, Zhang C (2019) Response of rhizosphere microbial communities to plant succession along a grassland chronsequence in a semiarid area. J Soils Sediments 19:2496- 
2508. https://doi.org/10.1007/s11368-019-02241-6

59. Speirs LBM, Rice DTF, Petrovski S, Seviour RJ (2015) The phylogeny, biodiversity, and ecology of the Chloroflexi in activated sludge. Front Microbiol 10:1-28. https://doi.org/10.3389/fmicb.2019.02015

60. Stegen JC, Lin XJ, Fredrickson JK, Chen XY, Kennedy DW, Murray CJ, Rockhold ML, Konopka A (2013) Quantifying community assembly processes and identifying features that impose them. ISME J 7:2069-2079. https://doi.org/10.1038/ismej.2013.93

61. Sterkenburg E, Chemmensen KE, Ekblad A, Finlay RD, Lindahl BD (2018) Contrasting effects of ectomycorrhizal fungi on early and late stage decomposition in a boreal forest. ISME J 12:21872197. https://doi.org/10.1038/s41396-018-0181-2

62. Toju H, Tanabe AS, Sato H (2018) Network hubs in root-associated fungal metacommunities. Microbiome 6:1-16. https://doi.org/10.1186/s40168-018-0497-1

63. Tripathi BM, Stegen JC, Kim M, Dong K, Adams JM, Lee YK (2018) Soil pH mediates the balance between stochastic and deterministic assembly of bacteria. ISME J 12:1072-1083. https://doi.org/10.1038/s41396-018-0082-4

64. Urbanová M, Šnajdr J, Baldrian P (2015) Composition of fungal and bacterial communities in forest litter and soil is largely determined by dominant trees. Soil Biol Biochem 84:5364. https://doi.org/10.1016/j.soilbio.2015.02.011

65. Vályi K, Mardhiah U, Rillig MC, Hempel S (2016) Community assembly and coexistence in communities of arbuscular mycorrhizal fungi. ISME J 10:2341-2351. https://doi.org/10.1038/ismej.2016.46

66. Varenius K, Kårèn B, Lindahl B, Dahlberg A (2016) Long-term effects of tree harvesting on ectomycorrhizal fungal communities in boreal Scots pine forest. Forest Ecol Manag 380:4149. https://doi.org/10.1016/j.foreco.2016.08.006

67. Wang HH, Chu HL, Dou Q, Feng H, Tang M, Zhang SX, Wang CY (2021) Seasonal changes in Pinus tabuliformis root-associated fungal microbiota drive $\mathrm{N}$ and $\mathrm{P}$ cycling in terrestrial ecosystem. Front Microbiol 11:1-14. https://doi.org/10.3389/fmicb.2020.526898

68. Wang J, Liao LR, Wang GL, Liu HF, Wu Y, Liu GB, Zhang C (2022) N-induced root exudates mediate the rhizosphere fungal assembly and affect species coexistence. Sci Total Environ 804:1-13. https://doi.org/10.1016/j.scitotenv.2021.150148

69. Wang YD, Wang ZL, Zhang QZ, Hu N, Li ZF, Lou YL, Li Y, Xue DM, Chen Y, Wu CY, Zou CB, Kuzyakov Y (2018) Long-term effects of nitrogen fertilization on aggregation and localization of carbon, nitrogen and microbial activities in soil. Sci Total Environ 624:1131-1139. https://doi.org/10.1016/j.scitotenv.2017.12.113

70. Xiong JB, Wu LY, Tu SX, Van Nostrand JD, He ZL, Zhou JZ, Wang GJ (2010) Microbial communities and functional genes associated with soil arsenic contamination and the rhizosphere of the ArsenicHyperaccumulating plant Pteris vittata L. Appl Environ Microbiol 76:7277-7284. https://doi.org/10.1128/Aem.00500-10 
71. Xiong QQ, Hu JL, Wei HY, Zhang HC, Zhu JY (2021) Relationship between plant roots, rhizosphere microorganisms, and nitrogen and its special focus on rice. Agriculture 11:1-18. https://doi.org/10.3390/agriculture11030234

72. Xu MP, Gao DX, Fu SY, Lu XQ, Wu SJ, Han XH, Yang GH, Feng YZ (2020) Long-term effects of vegetation and soil on the microbial communities following afforestation of farmland with Robinia pseudoacacia plantations. Geoderma 367:1-11. https://doi.org/10.1016/j.geoderma.2020.114263

73. Xun WB, Liu YP, Li W, Ren Y, Xiong W, Xu ZH, Zhang N, Miao YZ, Shen QR, Zhang RF (2021) Specialized metabolic functions of keystone taxa sustain soil microbiome stability. Microbiome 9:115. https://doi.org/10.1186/s40168-020-00985-9

74. Yin YC, Yan ZZ (2020) Variations of soil bacterial diversity and metabolic function with tidal flat elevation gradient in an artificial mangrove wetland. Sci Total Environ 718:1-11. https://doi.org/10.1016/j.scitotenv.2020.137385

75. Zeng YH, Feng FY, Medová H, Dean J, Koblížk M (2014) Functional type 2 photosynthetic reaction centers found in the rare bacterial phylum gemmationadetes. PNAs 111:7795-7800. https://doi.org/10.1073/pnas.1400295111

76. Zhang M, Dong LG, Wang Y, Bai XX, Ma ZT, Yu X, Zhao Z (2021) The response of soil microbial communities to soil erodibility depends on the plant and soil properties in semiarid regions. Land Degrad Dev 32(11):3180-3193. https://doi.org/10.1002/ldr.3887

77. Zhang C, Li J, Wang J, Liu GB, Wang GL, Guo L, Peng SZ (2019) Decreased temporary turnover of bacterial communities along soil depth gradient during a 35-year grazing exclusion period in a semiarid grassland. Geoderma 351:49-58. https://doi.org/10.1016/j.geoderma.2019.05.010

78. Zheng W, Zhao ZY, Lv FL, Wang RZ, Wang ZH, Zhao ZY, Li ZY, Zhai BN (2021) Assembly of abundant and rare bacterial and fungal sub-communities in different soil aggregate sizes in an apple orchard treated with cover crop and fertilizer. Soil Biol Biochem 156:1-13.

https://doi.org/10.1016/j.soilbio.2021.108222

79. Zhong ZK, Zhang XY, Wang X, Fu SY, Wu SJ, Lu XQ, Ren CJ, Han XH, Yang GH (2020) Soil bacteria and fungi respond differently to plant diversity and plant family composition during the secondary succession of abandoned farmland on the Loess Plateau, China. Plant Soil 448:183200. https://doi.org/10.1007/s11104-019-04415-0

80. Zhou JZ, Ning DL (2017) Stochastic community assembly: Does it matter in microbial ecology? Microbiology Mol Biol R 81:1-32. https://doi.org/10.1128/MMBR.00002-17

81. Zhu BJ, Li CN, Wang JM, Li JB, Li XZ (2020) Elevation rather than season determines the assembly and co-occurrence patterns of soil bacterial communities in forest ecosystems of Mount Gongga. Appl Microbiol Biot 104(17):7589-7602. https://doi.org/10.1007/s00253-020-10783-w

\section{Figures}


a Chronosequence $: R^{2}=0.339^{\star \star \star}$ Soil compartment $: R^{2}=0.122^{\star \star \star} b$

Chronosequence $: R^{2}=\mathbf{0 . 2 5 2 ^ { \star \star }}$ Soil compartment $: R^{2}=\mathbf{0 . 0 4 8}$
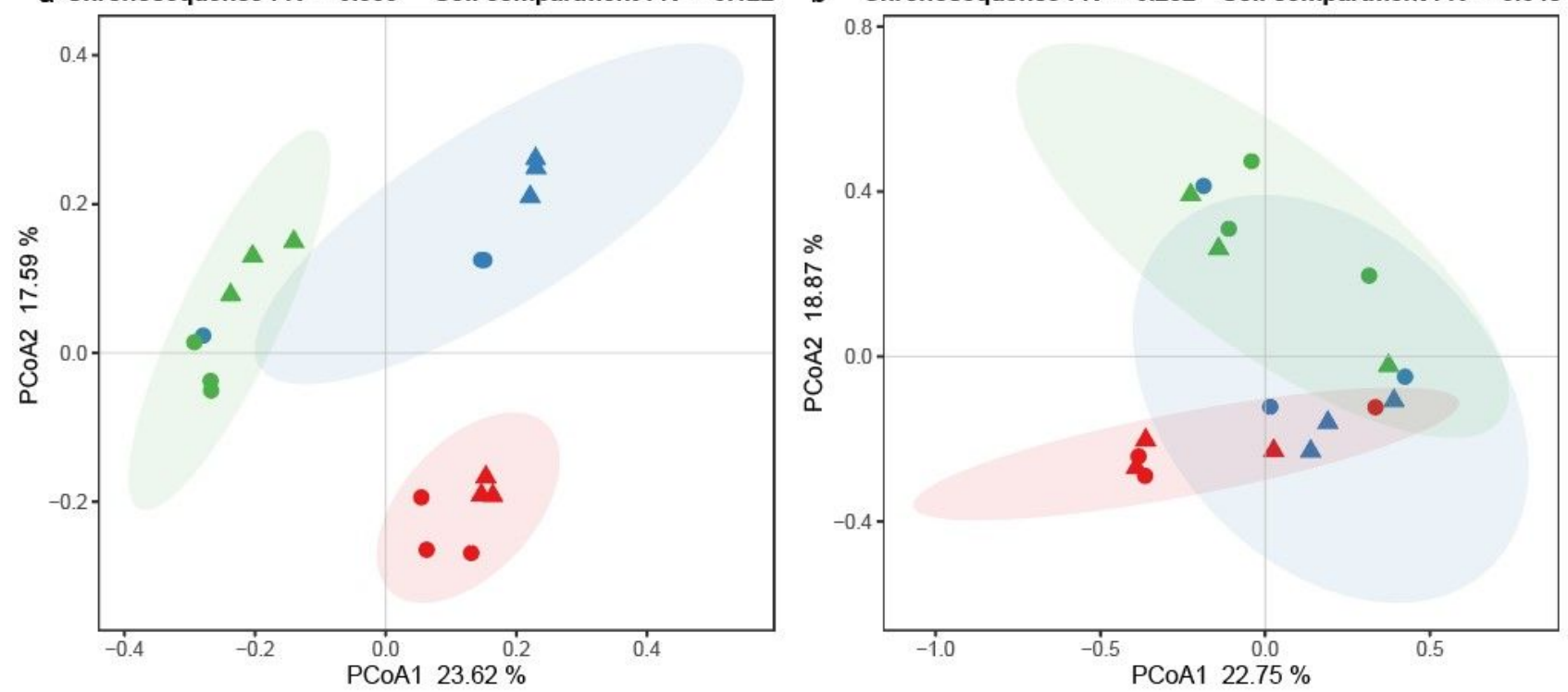

Chronosequence

- $15 \mathrm{Y}$

- $30 \mathrm{Y}$

- $60 \mathrm{Y}$

Soil compartment

- BS

$\Delta$ RS

Figure 1

Principal co-ordinates analysis (PCoA) of soil bacterial (a) and fungal (b) community composition based on Bray-Curtis distance. 15Y, 15 years-old; 30Y, 30 year-old; 60Y, 60 year-old; BS, bulk soil; RS, rhizosphere soil. * $P<0.05$, ** $P<0.01$, *** $P<0.001$.
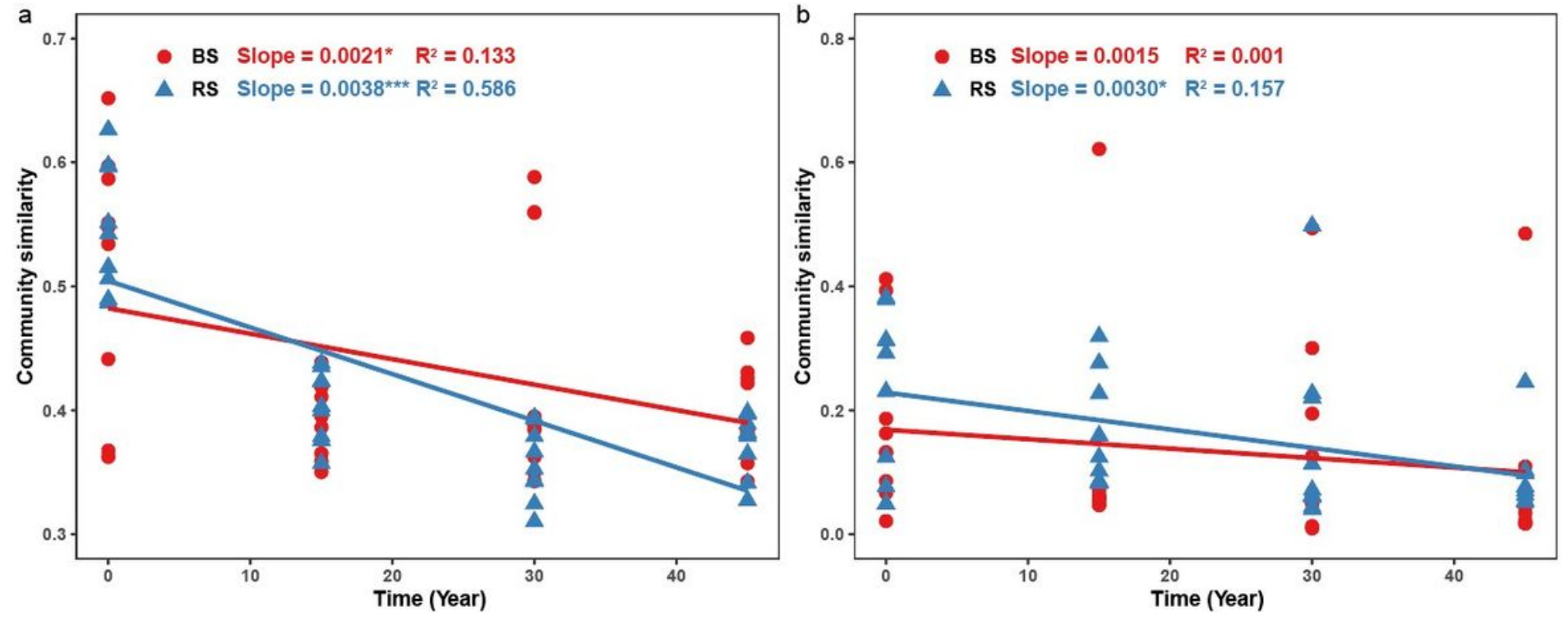

Figure 2

Time-decay relationships for bacterial (a) and fungal (b) community across the chronosequence in different soil compartments. BS, bulk soil; RS, rhizosphere soil. ${ }^{*} P<0.05$, ${ }^{\star \star} P<0.01$, ${ }^{\star \star \star} P<0.001$. 


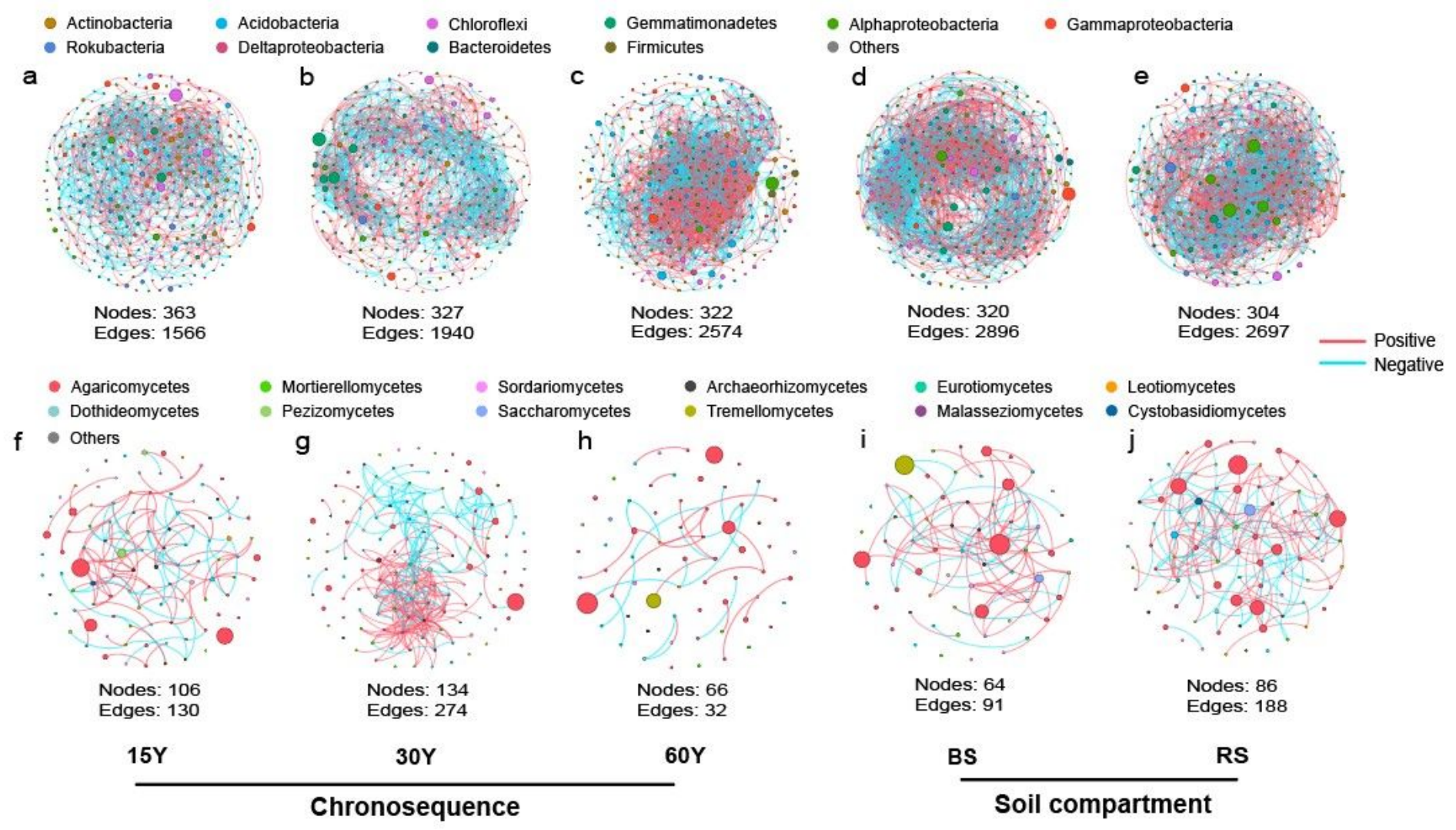

\section{Figure 3}

Bacterial (a-e) and fungal (f-j) co-occurrence networks across the chronosequence and soil compartment. Nodes represent ASVs. Edges indicate significant correlations (SparCC greater than 0.7 or less than -0.7 with $P$ value $<0.01$ ). The colors of nodes indicate different taxa they belonging to. The size of each node represents its relative abundance. $15 \mathrm{Y}, 15$ years-old; $30 \mathrm{Y}, 30$ year-old; $60 \mathrm{Y}, 60$ year-old; BS, bulk soil; RS, rhizosphere soil. 

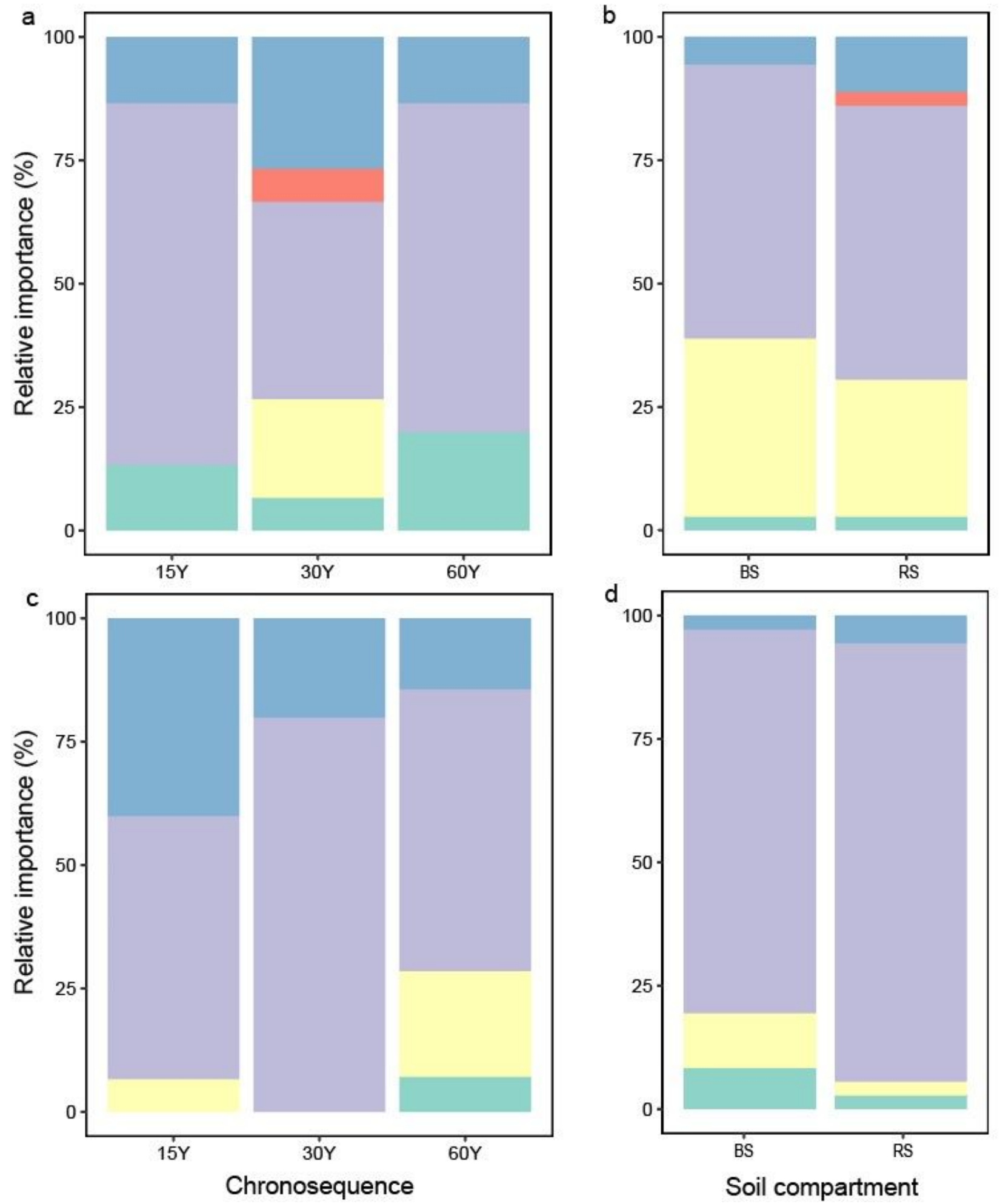
DR
HD
$\mathrm{DL}$
HoS
$\mathrm{HeS}$

\section{Figure 4}

The relative importance of ecological processes bacterial $(a, b)$ and fungal $(c, d)$ community assembly across the chronosequence and soil compartment. $15 \mathrm{Y}, 15$ years-old; $30 \mathrm{Y}, 30$ year-old; $60 \mathrm{Y}, 60$ year-old; BS, bulk soil; RS, rhizosphere soil; HeS, heterogeneous selection; HoS, homogeneous selection; DL, dispersal limitation; HD, homogenizing dispersal; DR, drift. 

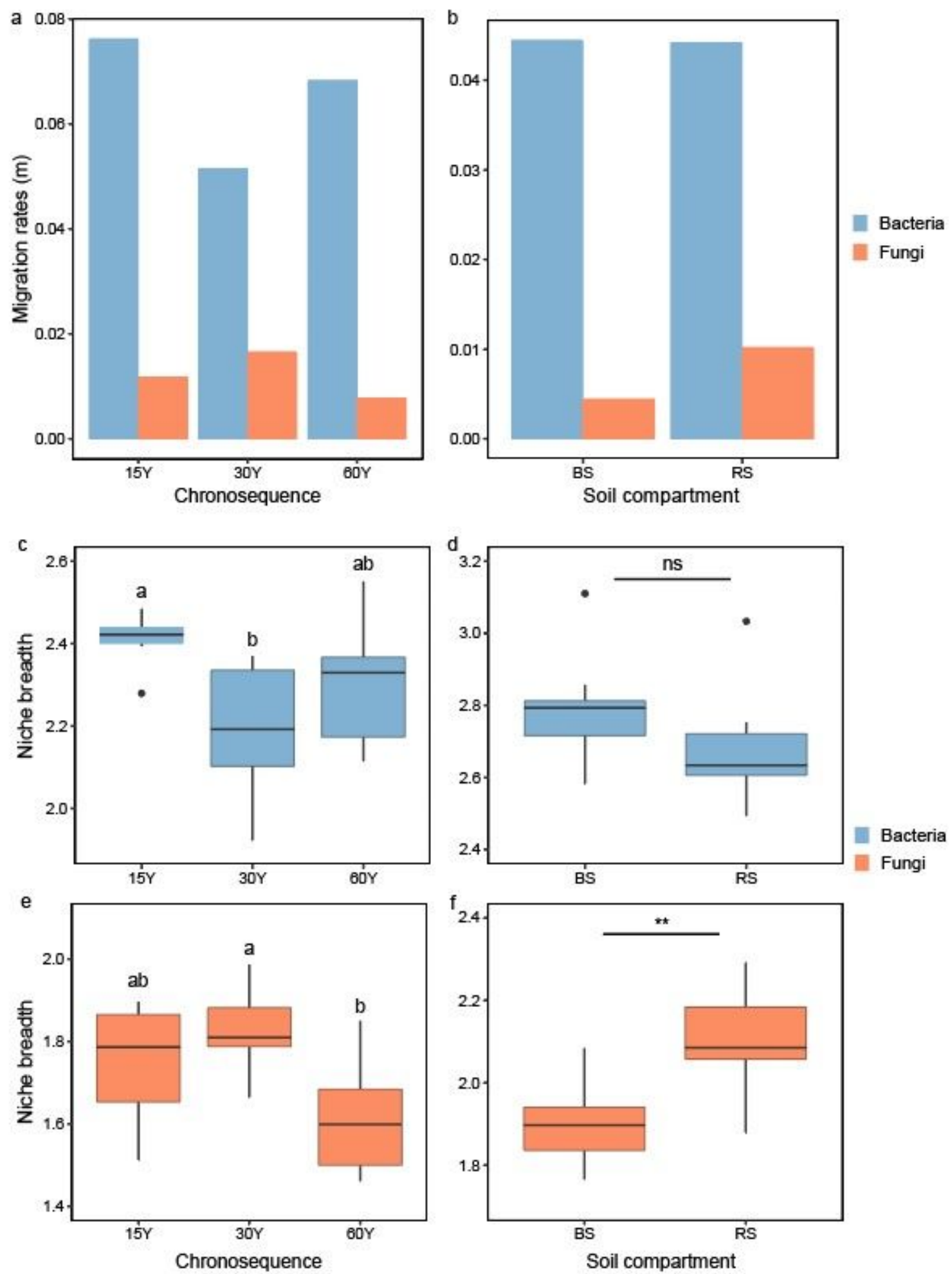

\section{Figure 5}

Multiple biological models showing microbial community assembly across the chronosequence and soil compartment. Migration rates $(\mathrm{m})$ value based on neutral model of bacteria and fungi across the chronosequence (a) and soil compartment (b). Habitat niche breadth of bacterial (c, d) and fungal (e, f) communities across the chronosequence and soil compartment. 15Y, 15 years-old; 30Y, 30 year-old; 60Y, 
60 year-old; $B S$, bulk soil; RS, rhizosphere soil. Different letters indicate significant difference with $(P<$ 0.05). ns, not significantly different; ${ }^{*} P<0.05$, ${ }^{\star *} P<0.01$, *** $P<0.001$.

\section{Supplementary Files}

This is a list of supplementary files associated with this preprint. Click to download.

- Supplementalmaterials11.19.docx 